\title{
Relying on suction to maintain slope stability
}

\author{
AB Fourie The University of Western Australia, Australia
}

\begin{abstract}
The stability of open pit slopes in saprolitic materials may be enhanced by ensuring the slopes remain as dry as possible. This is because, when the saprolite remains dry or relatively dry, negative pore water pressures, also known as suctions, may contribute significantly to the stability of these slopes. Simple actions to retain the slopes as dry as possible, particularly in zones of the slopes where critical shear zones develop are described. Additional complications are due to the existence of cemented bonds in undisturbed saprolites. These bonds are remnant from the original, parent bedrock and may provide a very brittle response when subjected to loading. The need to separate the contribution of these various factors to the shear strength of saprolites is essential to correctly quantifying the stability of slopes in saprolitic materials.
\end{abstract}

\section{Introduction}

Open pits often expose deep profiles of weathered rock. The degree of weathering may be significant enough to render the application of traditional rock mechanics principles inapplicable. However, the weathered material is not a soil either, at least in the classical sense that is embodied in many principles of soil mechanics, with these principles having been derived principally for transported soils. Residual features of the parent bedrock are often still present in these materials, providing some component of available shear strength. What complicates matters further, at least in many open pits in Australia, is the development of negative pore water pressures (i.e. suctions) in material, a factor that further contributes to available shear strength. However, a decision to rely on this suction in the design of open pit slopes cannot be taken lightly, as factors may contribute to reduce suction to very low values (or even zero), rendering the shear strength lower than predicted. This paper explores the nature of the strength contribution due to suction and the conditions under which it might be possible to rely on this strength contribution.

\section{$2 \quad$ Origin of weathered profiles}

The term 'residual soil' is often used to describe the material of interest, where formation of the profile is due to in situ weathering. The weathering is chemical (rather than physical) in nature, occurring in regions of (past or present) high temperatures and high rates of rainfall (Toll 2012). The degree of weathering is described by six categories, describing the decomposition of intact rock (Grade I) through to Grade $\mathrm{VI}$, which is essentially a soil. The upper three grades, i.e. VI (residual soil), V (completely weathered) and IV (highly weathered) represent materials where weathering has decomposed more than $50 \%$ of the rock to form soil. The term 'saprolite' is widely used, often incorrectly. According to Toll (2012), the term is used to describe completely and highly weathered material, i.e. a soil that still contains some unweathered rock but does not include the Grade VI category, residual soil. It therefore retains some features of the parent bedrock, features that contribute to the shear strength of the material but make applications of classical soil mechanics or rock mechanics principles difficult.

Saprolites are often highly structured, with the structure resulting from leaching of minerals during the weathering process. This often leaves a relatively open structure, with in situ void ratios sometimes exceeding values of two. Additionally, deposition of minerals during or after weathering has occurred may result in secondary cementation (thus providing a strength contribution in addition to that provided by remaining bedrock features). This cementing action can maintain the saprolite in a stable state despite the high void ratios. However, damage to the cemented bonds may result in a rapid loss of strength, sometimes leading to sudden volume changes. If the saprolite material is saturated (e.g. below the water table), the 
volume decrease is resisted by an increase in pore water pressure, potentially resulting in a sudden failure, often termed static liquefaction. An additional, complicating feature is that during the weathering process, silica and bases are lost in solution or incorporated into clay minerals. It is thus not uncommon to find high amounts of clay minerals (true clay minerals and not just clay-sized particles) in saprolite profiles. The structured nature of saprolites means, for example, the application of conventional soil mechanics constitutive models, such as Modified Cam-clay are inappropriate; these models take no account of the contribution of cemented bonds to strength.

Two examples of the clay mineralogy of saprolites are given in Table 1, one from West Africa, the other from New Caledonia.

Table 1 Properties of saprolites from two sites, illustrating the importance of clay mineralogy and the high in situ void ratios

\begin{tabular}{|c|c|c|}
\hline Site & West Africa & New Caledonia \\
\hline Liquid limit (\%) & $41-45$ & 79 \\
\hline Plasticity index (\%) & $33-35$ & 35 \\
\hline Specific gravity & 2.7 & 2.69 \\
\hline Void ratio & $0.78-1.09$ & 1.8 \\
\hline In situ degree of saturation (\%) - wet season & 89 & 95 \\
\hline USCS classification & ML & $\mathrm{MH}$ \\
\hline Mineralogy (in order of decreasing proportion) & $\begin{array}{l}\text { Quartz, kaolinite, illite, } \\
\text { microcline }\end{array}$ & \\
\hline
\end{tabular}

There are a few points to note in regards to the data in Table 1. Firstly, classification schemes such as the Unified Soil Classification System (USCS) system are based on measurements on remoulded (i.e. destructured) samples, e.g. particle size distribution tests and Atterberg limit tests. Such classification schemes cannot thus account for the structure of saprolites, i.e. features such as cementing and the high in situ void ratios. Reliance on empirical correlations of engineering behaviour with the USCS classification is thus not advised. What makes the situation even more complex is that many residual soils and saprolites are sensitive to the method of sample preparation, such as air drying versus oven drying. As discussed by Fourie (1997) and Fookes (1997), these effects can produce very significant differences in the values of the Atterberg limits (and indeed even the particle size distribution) measured.

\section{Actual versus apparent cohesion}

The effective stress approach to slope stability analysis defines the available shear strength $\tau_{f}$ as follows:

$$
\tau_{f}=c^{\prime}+\sigma^{\prime} \tan \phi^{\prime}
$$

where: $c^{\prime}$ is the apparent cohesion, $\sigma^{\prime}$ is the effective stress and $\phi^{\prime}$ the angle of internal friction.

To define effective stress parameters for use in a stability evaluation, it is common to carry out triaxial tests on similar specimens, each specimen being subjected to a different effective confining stress. The higher the confining stress, the higher the available peak shear strength. Results are plotted in terms of Mohr circles, as shown in Figure 1. In this figure, the solid half-circles represent the stresses from three different triaxial tests. A straight line is fitted as closely as possible to be tangent to the Mohr Circles (usually drawn for the stress at which the sample fails, i.e. the peak shear stress), thus defining $c^{\prime}$ and $\phi^{\prime}$ as shown. 


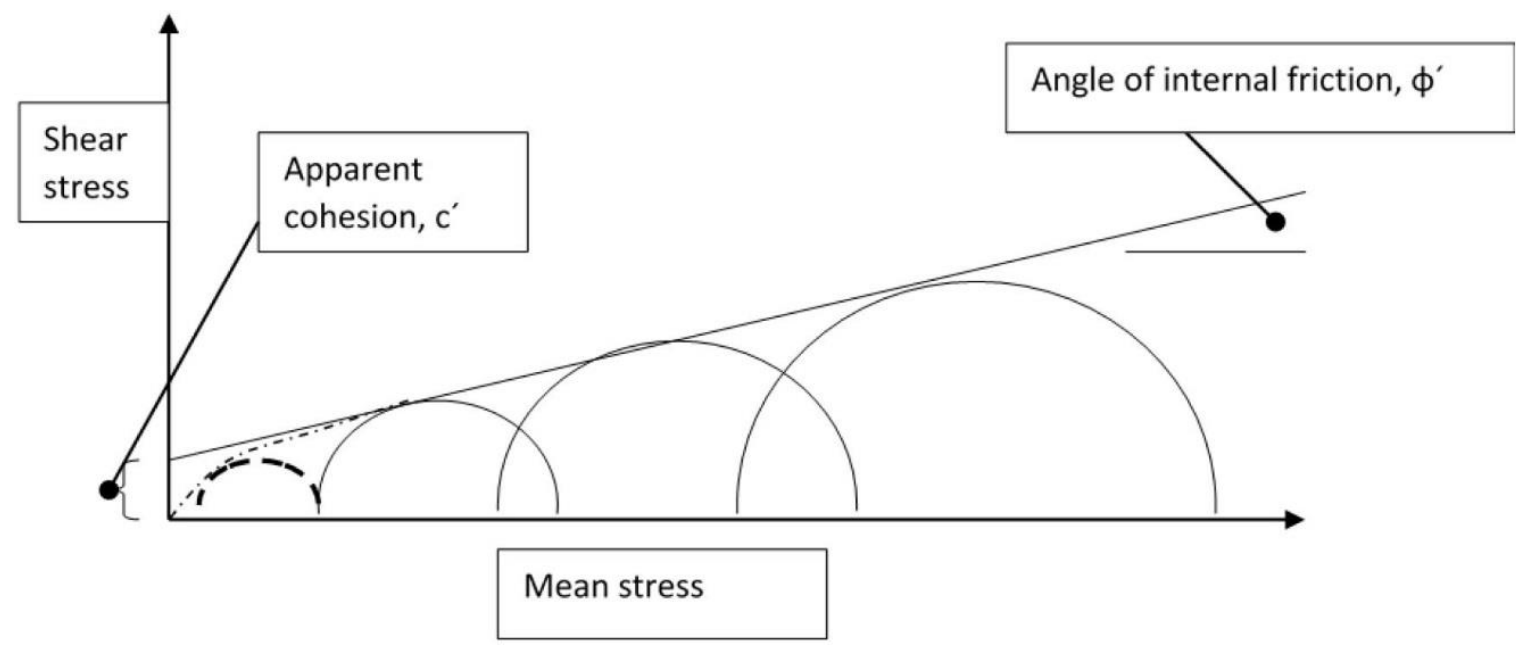

Figure 1 Illustration of definition of effective stress strength parameters

It is perhaps not always appreciated that the apparent cohesion $c^{\prime}$ is in fact nothing more than a convenience. It is convenient because it allows a straight line to be fitted to experimental data, thus providing a relatively simple relation between shear strength and the effective stress strength parameters. However, in reality, at low effective stresses the failure envelope is often curved, as shown by the dotted Mohr circle and dotted failure envelope in Figure 1. At low effective stresses (e.g. near the surface) this curvature of the failure envelope may be important; at greater depth (where critical slip surfaces may develop) it is usually unimportant, because effective stresses are much higher.

When discussing saprolites we therefore need to differentiate between true cohesion and apparent cohesion. True cohesion may be provided by the cemented bonds that, as discussed in this paper, provide additional shear strength. This is a true cohesion and can be relied on even at low effective stresses (i.e. near the surface) as long as the bonds remain intact. An example of a triaxial test on a saprolite from the mine in West Africa referred to earlier is shown in Figure 2.

\section{Shear stress (kPa)}

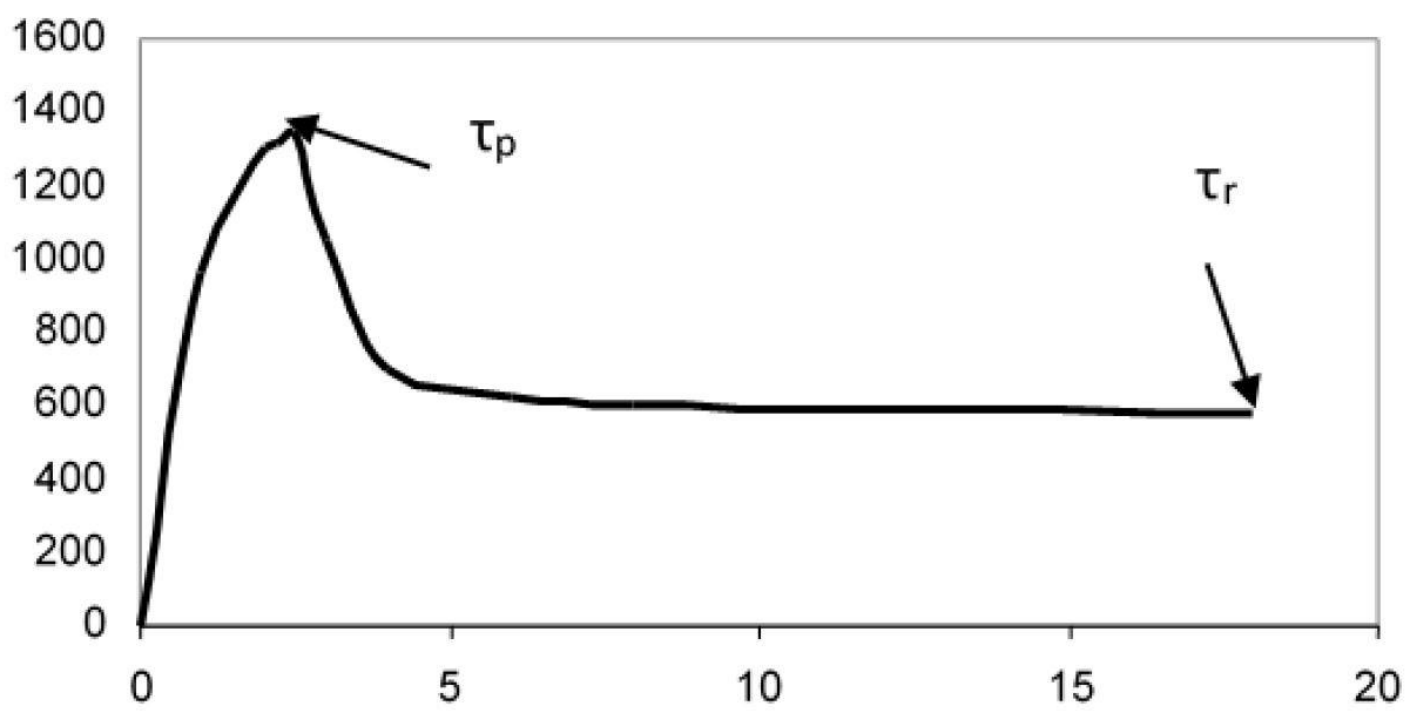

Axial strain (\%)

Figure 2 Results from a triaxial test on saprolite specimen from West Africa, illustrating the peak shear strength $\tau_{f p}$ and the destructured shear strength $\tau_{f r}$ 
The peak shear strength $\tau_{f p}$ is mobilised at relatively small strains ( $<5 \%$ strain), and this component of strength depends primarily on the true cohesion, i.e. the cemented bonds. As shown by Wang and Leung (2008), the frictional resistance only becomes fully mobilised once the cemented bonds are substantially destroyed, which occurs after the peak strength is mobilised. When plotting Mohr circles to determine shear strength parameters for materials such as saprolites it is therefore important to distinguish between peak conditions and destructured conditions. Note that the term 'destructured' strength has been used in this paper rather than 'residual' strength because the latter term is usually reserved for the condition typically exhibited by clays, where large displacements result in an ever more substantial decrease in frictional resistance, until some final, residual value is eventually reached.

An important consideration when designing a slope in a saprolite profile is that the peak shear strength may be mobilised at relatively small displacements. Strength mobilisation may thus be displacement driven, rather than loading-driven, which is usually the case in applications such as foundation design. During excavation of an open pit, removal of overburden material results in some uplift at the base of the pit due to stress relief, although this may often be imperceptible. It also results in displacements of the slope towards the void as the excavation becomes deeper. Depending on factors such as in situ stresses and material stiffness, these displacements may conceivably be large enough to mobilise the peak shear strength, followed of course by strain softening towards the destructured strength.

\section{$4 \quad$ Contribution of suction to shear strength}

The additional shear strength provided by the true cohesion component of strength is one of two possible 'cohesion' contributors when considered excavation of a slope in saprolites. The second is suction, also referred to as negative pore water pressure.

A saprolitic material may often be only partially saturated, meaning that the voids are filled with both water and air. In this unsaturated condition, the water phase is retained in the saprolite by a negative pressure (negative relative to atmospheric pressure), called suction. Suction may contribute significantly to shear strength, in addition to influencing the hydraulic conductivity of a saprolite.

Suction is actually comprised of two components, osmotic suction and matric suction, the sum of which is known as total suction. Osmotic suction occurs due to the presence of dissolved salts within the pore water, particularly when there is a concentration gradient of salts. For the purposes of this paper, attention is restricted to matric suction $(\psi)$, which develops due to surface tension at the interfaces between water and air phases present in unsaturated saprolites, i.e. $\psi=\left(u_{a}-u_{w}\right)$, where $u_{a}$ and $u_{w}$ are the pressure in the air and water phase respectively. The magnitude of suction is a function of the volumetric water content of the material, with suction increasing as water content decreases. Note that volumetric water content, $\theta$, differs from the geotechnical definition of water content, and $\theta=V_{w} / V$, where $V_{w}$ and $\mathrm{V}$ are the volume of water and total volume respectively. The relationship between $\psi$ and $\theta$ is invariably highly non-linear. An example is shown in Figure 3. Note the scale for suction is logarithmic.

Notice from Figure 3 that when the volumetric water content approaches the maximum value (which is equal to the porosity), the suction drops to zero, meaning that if the saprolite becomes fully saturated there will be zero suction. 


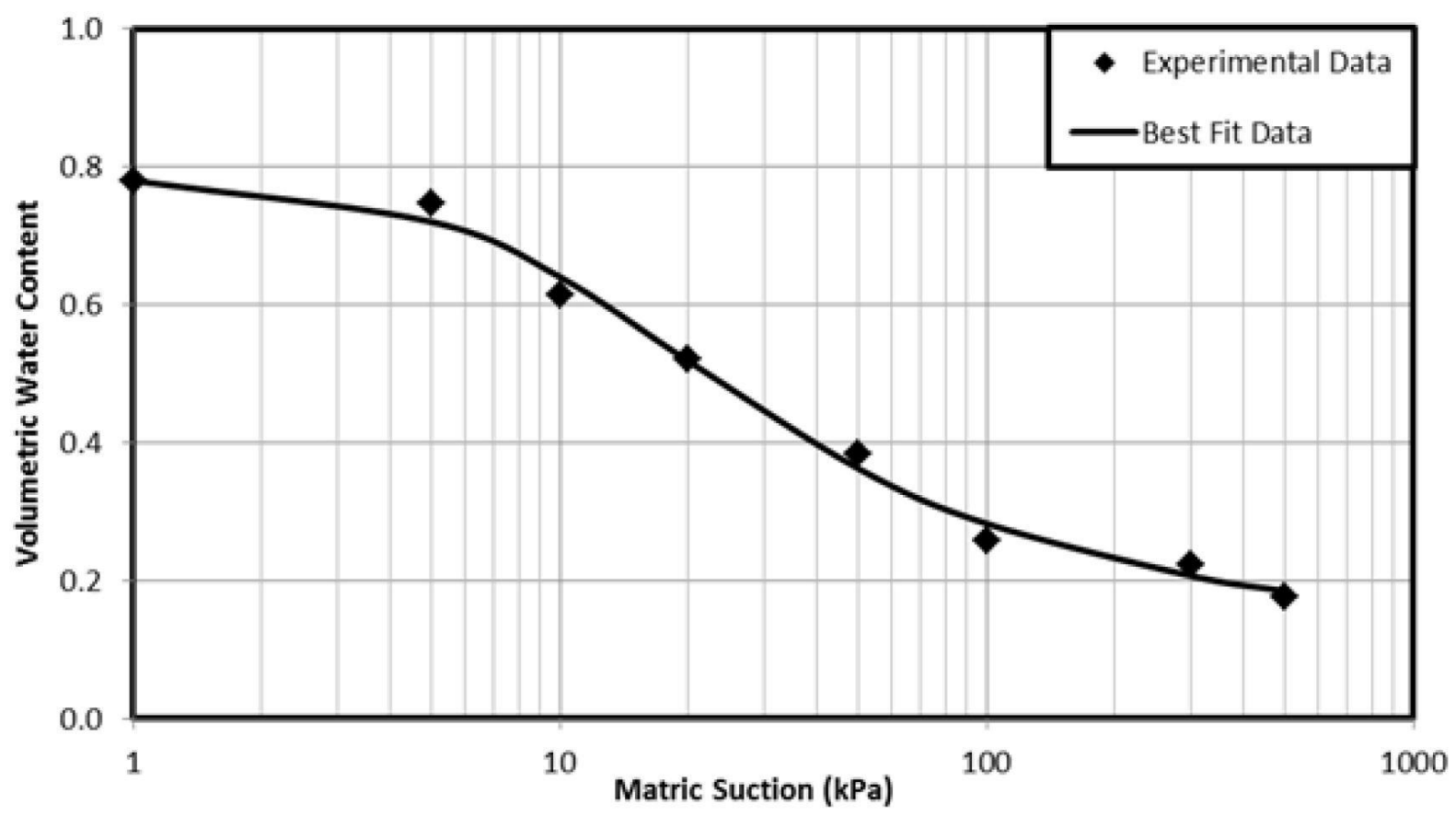

Figure 3 Illustration of the relationship between volumetric water content and matric suction

The equation for shear strength shown in Equation (1) is often modified to account for suction as follows (Fredlund et al. 1978):

$$
\tau_{f}=c^{\prime}+\left(\sigma-u_{a}\right) \tan \phi^{a}+\left(u_{a}-u_{w}\right) \tan \phi^{b}
$$

where: $\phi^{\mathrm{a}}$ is the angle of friction for changes in net stress ( $\sigma$-ua), and $\phi b$ is the angle of friction for changes in matrix suction (ua-uw), and the other parameters are as earlier defined before.

This approach treats the effects of net stress and suction differently, and assigns different contributions of friction to the two components of stress. The resulting three-dimensional representation of the extended Mohr-Coulomb failure surface is illustrated in Figure 4.

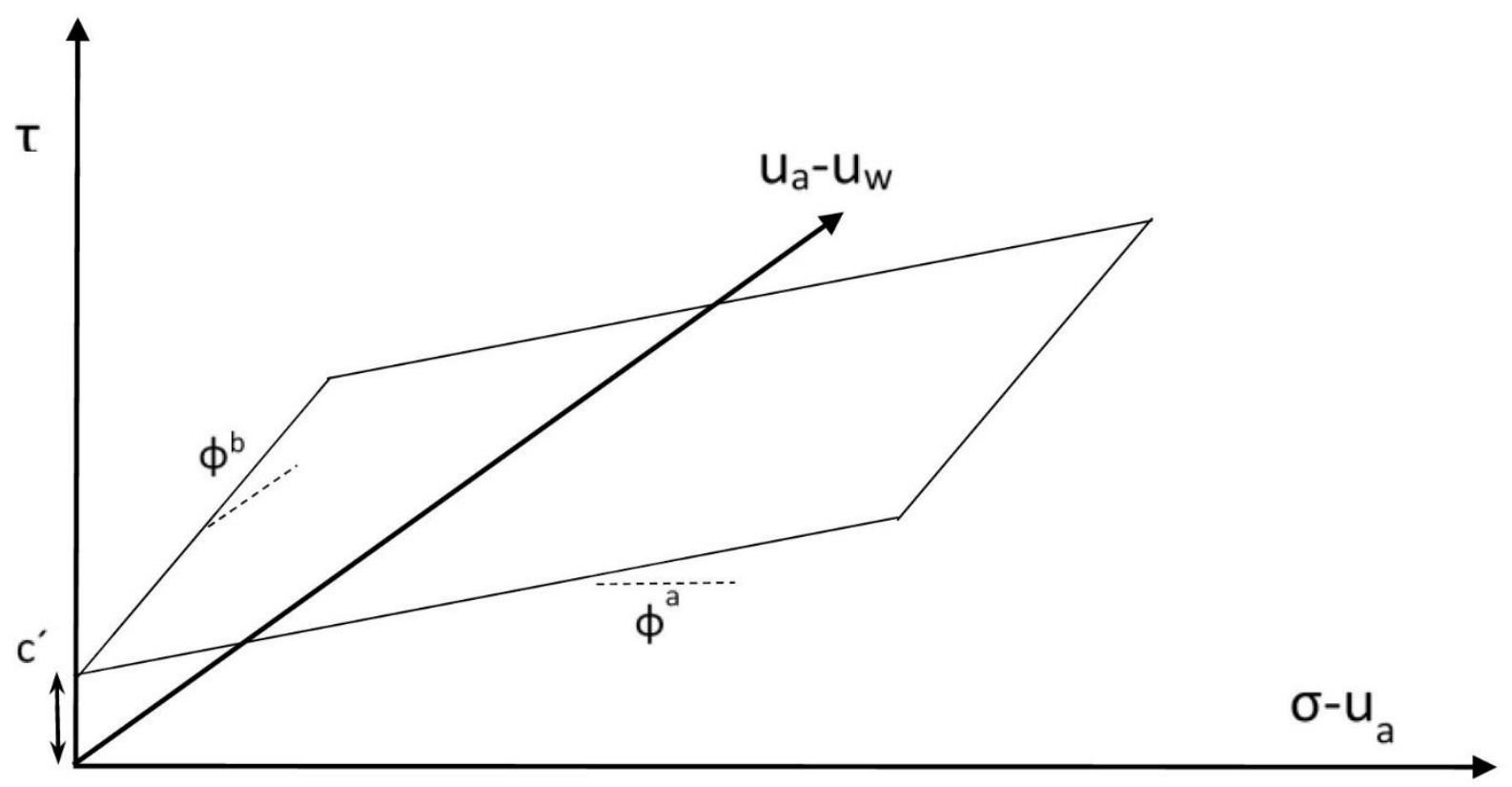

Figure 4 Extended Mohr-Coulomb failure envelope, illustrating contribution of matric suction toe shear strength 
The relationship between $\phi^{b}$ and matric suction is generally non-linear (e.g. Fredlund et al. 1987). If the material remains saturated, but at a volumetric water content below the air entry value, $\phi^{\mathrm{b}}$ can be taken to be equal to $\phi^{\prime}$, but once air begins to enter the pore voids, $\phi^{\mathrm{b}}$ decreases. Although there is no consensus on this approach to accounting for the contribution of suction to shear strength, the advantage is that it has been included in some limit equilibrium software codes, such as SEEP/W and Soilvision.

Measurement of $\phi^{\mathrm{b}}$ is not a trivial matter and is beyond the scope of this paper. Instead, the contribution of suction to shear strength is considered, as is the question of whether or not this contribution can be relied upon when designing slopes.

Figure 5 shows the projection of Figure 4 onto the plane $\tau-\left(\sigma-u_{a}\right)$, showing how suction increases the shear strength.

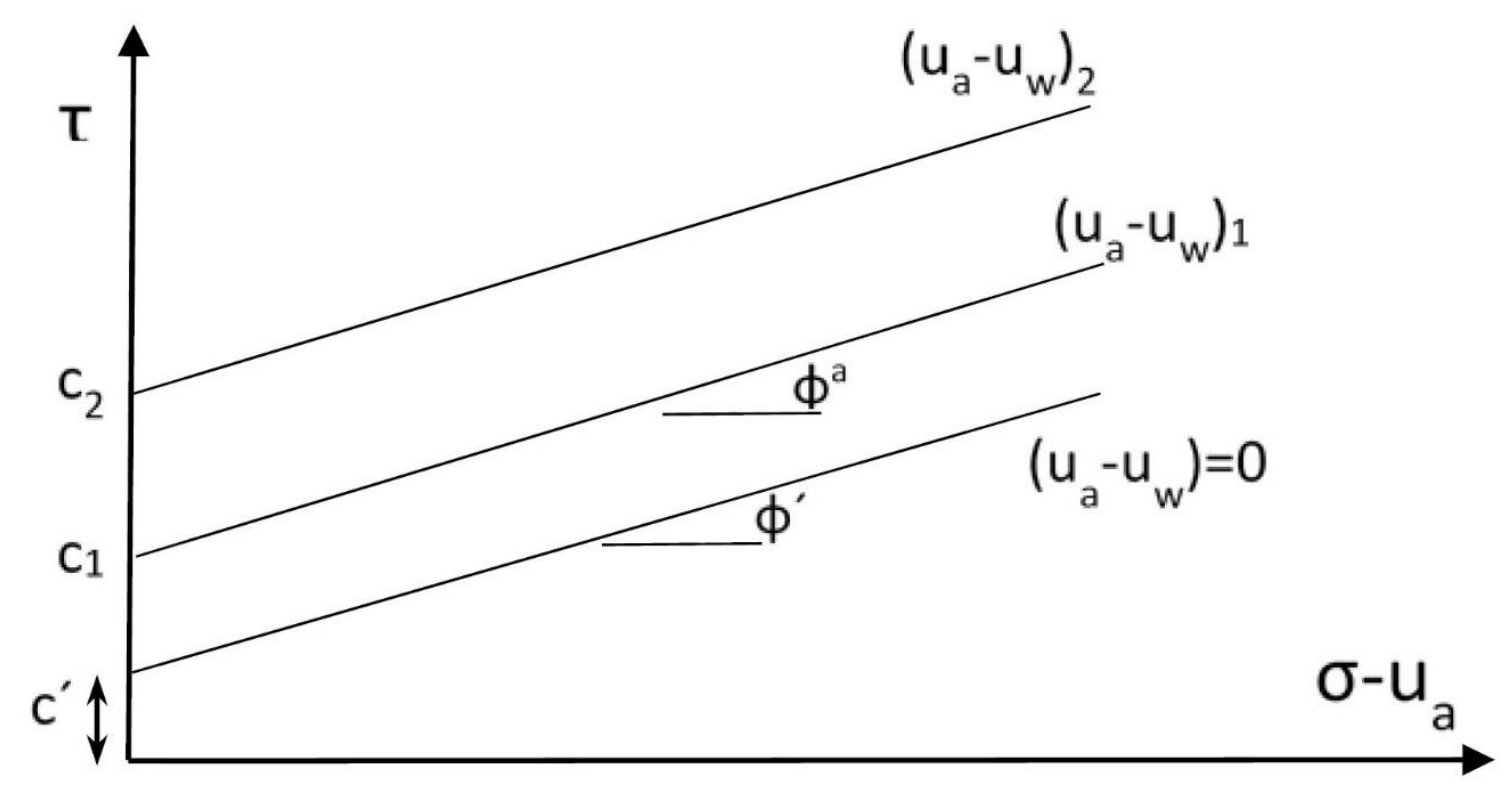

Figure 5 Extended Mohr-Coulomb failure envelope projected onto shear stress - net stress plane

In the stress space shown in Figure 5, the contribution of matric suction to shear stress can be considered as an additional cohesion contribution to strength - for purposes of facilitating discussion. Let the contribution to shear strength from suction, $\left(u_{a}-u_{w}\right) \tan \phi^{b}$, be represented by $C_{2}$. In the conventional Mohr-Coulomb representation of shear strength (Equation (1)), the first term on the right of the equality sign is then $c^{\prime}+C_{2}$. For saprolites, it is even more complex because there is the additional contribution to cohesion from the cemented bonds, as discussed earlier in the paper. If we designate this contribution as $C_{3}$, the total cohesion, $C$, comprises of three components, i.e. $C=\mathrm{C}^{\prime}+\mathrm{C}_{2}+\mathrm{C}_{3}$. Although this is useful to conceptualise the reasons that saprolites may sometimes remain stable at angles that defy simple limit equilibrium calculations based on parameters obtained from saturated triaxial or shear box tests, it is cumbersome to implement in practice. In truth, the situation is even more complicated because, when sheared, the material is likely to generate changes in pore water pressure and thus suction, changing the contribution of suction to available shear strength. To make progress on accounting for these various contributions to the total cohesion, the next section considers the contribution of matric suction to slope stability, but in the absence of bonding, i.e. $C_{3}=0$.

\section{Illustration of contribution of suction to slope stability}

Evaluation of potential shallow slope failures can be performed using Equation (2), (Fourie 1996).

$$
F=\frac{c^{\prime}+\left(\gamma_{t} z_{w}-u_{w}\right) \cos ^{2} \alpha \tan \phi^{\prime}}{\gamma_{t} z_{w} \sin \alpha \cos \alpha}
$$


where: $\mathrm{F}$ is the Factor of Safety, $c^{\prime}$ is the apparent cohesion, $\varphi^{\prime}$ is the internal friction angle, $\alpha$ is the slope angle, $\nu_{t}$ is the total unit weight of the soil, and $u_{w}$ is the pore water pressure. This simplified approach ignores the variable contribution of suction to strength, rather simply representing the pore water pressure $\left(u_{w}\right)$ as negative, to represent suction. By doing this, the evaluation of Factor of Safety reduces to an easily-solved equation. However, it must be noted that more detailed analyses should incorporate the more non-linear form of solution, as embodied in an equation such as Equation (2). Nevertheless, using this simplified approach allows illustration of the importance of suction to slope stability, and also how the effects of infiltration can reduce (perhaps eliminate) this same contribution.

The results summarised in Figure 6 are for planar, shallow potential failure surfaces. The parameters used in the slope stability analysis are $c^{\prime}=5 \mathrm{kPa}, \varphi^{\prime}=34^{\circ}$, slope angle $\alpha=45^{\circ}$ and $\gamma_{\mathrm{t}}=18 \mathrm{kN} / \mathrm{m}^{3}$. Results showed that the Factor of Safety decreases markedly with a reduction in matric suction, particularly at depths of less than $1 \mathrm{~m}$. The Factor of Safety also decreases significantly with the increase in failure depth. If this particular slope had an in situ suction of $40 \mathrm{kPa}$, the Factor of Safety would be acceptable for all potential depths of potential slip. However, were rainfall to start to occur, resulting in infiltration into the slope, the suction near the surface would decrease, while the suction at depth (initially) remained unchanged. If, for example, the suction decreased to $10 \mathrm{kPa}$ ahead of the wetting front, instability would be triggered at a depth of approximately $1.1 \mathrm{~m}$. This illustrates that it is not necessary for the slope to become fully saturated for a failure to occur. It only requires the suction to decrease below a critical value, a value that depends on soil strength and density and geometry of the slope.

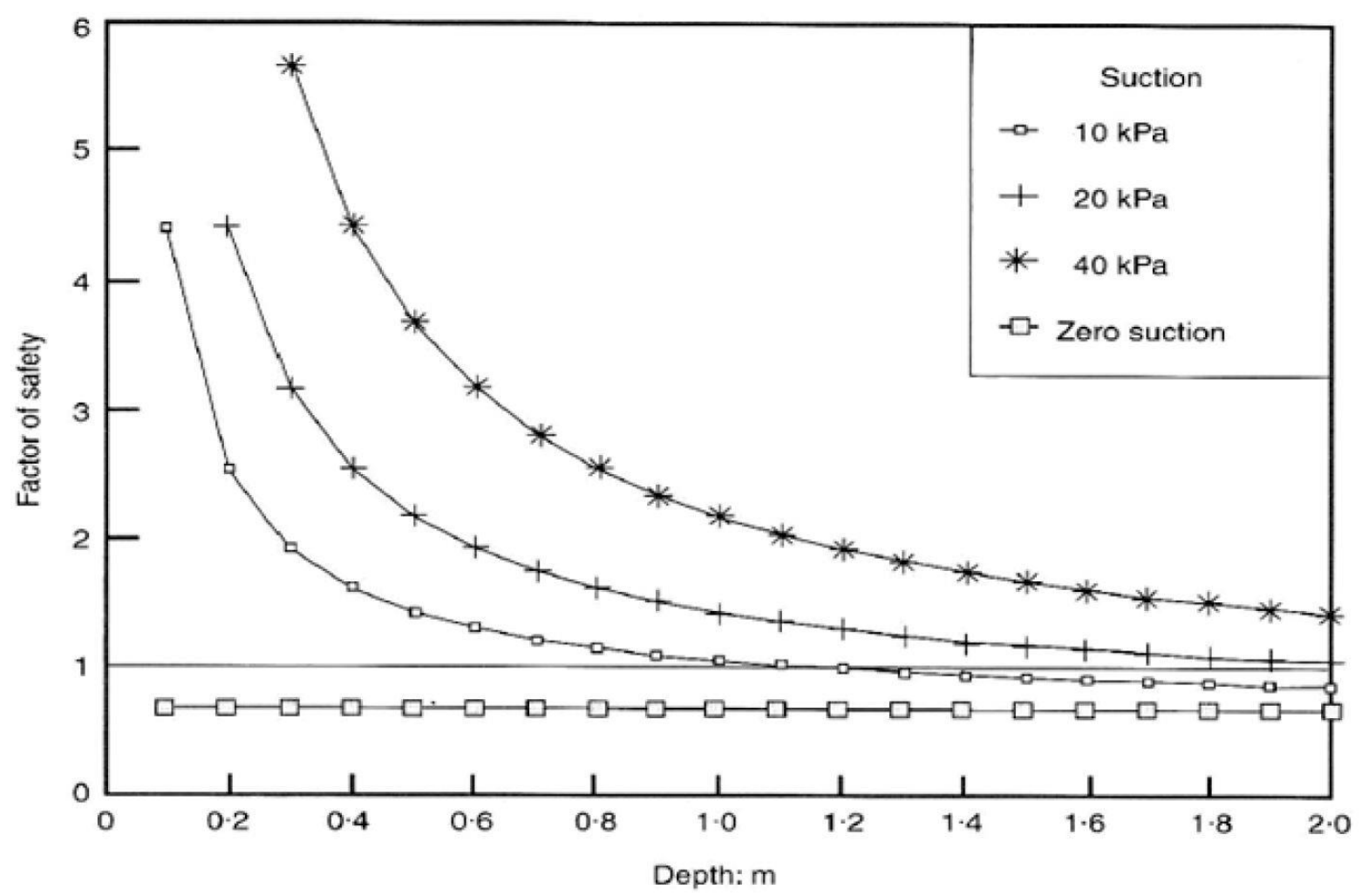

Figure 6 Illustration of how suction contributes to stability along shallow, planar surfaces

The results in Figure 6 illustrate conceptually how a decrease of suction can render an otherwise stable slope unstable. As the suction decreases, the shear strength decreases accordingly and eventually a critical condition may be reached. However, with saprolites, there may still be a significant contribution to stability provided by cohesion $\mathrm{C}_{3}$. In some saprolite slopes, infiltration may thus not be critical, as long as the strength provided by $\mathrm{C}_{3}$ cohesion remains intact. Determining the extent of damage to the $\mathrm{C}_{3}$ component (i.e. bond damage) is not a trivial undertaking. It would most likely entail the excavation of undisturbed blocks of material from the pit benches, with relevant testing then taking place to gauge the extent of bond damage. Clearly, this is unlikely to be viable, so alternatives need to be sought. 
Given the proliferation of radar monitoring of slopes, it is suggested that monitoring the cumulative deformation of all exposed pit walls would make it possible to estimate the amount of strain the saprolite within the slope (particularly near surface) had been exposed to. This could then be compared with the critical strains at which bonds begin to be destroyed in saturated specimens (the peak strength shown in Figure 2).

\section{Importance of strain range over which softening occurs}

In the software FLAC, it is possible to decrease both the friction angle and the cohesion (in this case cohesion $\mathrm{C}_{2}$ ) over a given strain range, i.e. it represents the destructuring observed in triaxial tests on the saprolites referred to earlier. The Mohr-Coulomb model in FLAC that provides this facility was used to analyse a slope that was based on the West African study referred to earlier. A $40^{\circ}$ slope was excavated into material by sequential layer removal. The strength parameters $c^{\prime}$ and $\phi^{\prime}$ were varied from measured peak values of $44 \mathrm{kPa}$ and $22^{\circ}$ respectively to measured destructured values of $22 \mathrm{kPa}$ and $16.6^{\circ}$. Destructuring was assumed to occur starting from zero strain, to final values at which softening was complete, referred to as the strain softening range in Table 2 .

Table 2 Strain ranges over which softening occurred, and excavation depths at which failure occurred in FLAC analyses

\begin{tabular}{|l|c|c|c|c|}
\hline Strain softening range (\%) & 0.1 & 1 & 10 & 100 \\
\hline Excavation depth at which failure occurred $(\mathbf{m})$ & 4 & 20 & 40 & Stable at $40 \mathrm{~m}$ \\
\hline
\end{tabular}

The results of this study, more details of which are given by Lao (2013) show that for brittle materials (where softening occurs over only $0.1 \%$ strain), failure occurs at a very shallow depth. This is because the slope angle is $40^{\circ}$ and softening brings the shear strength to low values very rapidly in this case. Contrary to this, for material for which softening was (unreasonably) protracted, i.e. requiring $100 \%$ strain for full softening, the slope remained stable even when the excavation depth was $40 \mathrm{~m}$. This illustrates the importance of potential strain-induced damage to the cohesion component $\mathrm{C}_{2}$.

Figure 7 illustrates the location of maximum strain obtained from the FLAC analyses and a simple explanation of how the yielded zone initiates at the toe of the slope and gradually extends upwards towards the ground surface. The inset to Figure 7 shows output from the FLAC analyses which illustrate the same situation, with the light coloured zones at the base of the slope being highest shear strain zones.

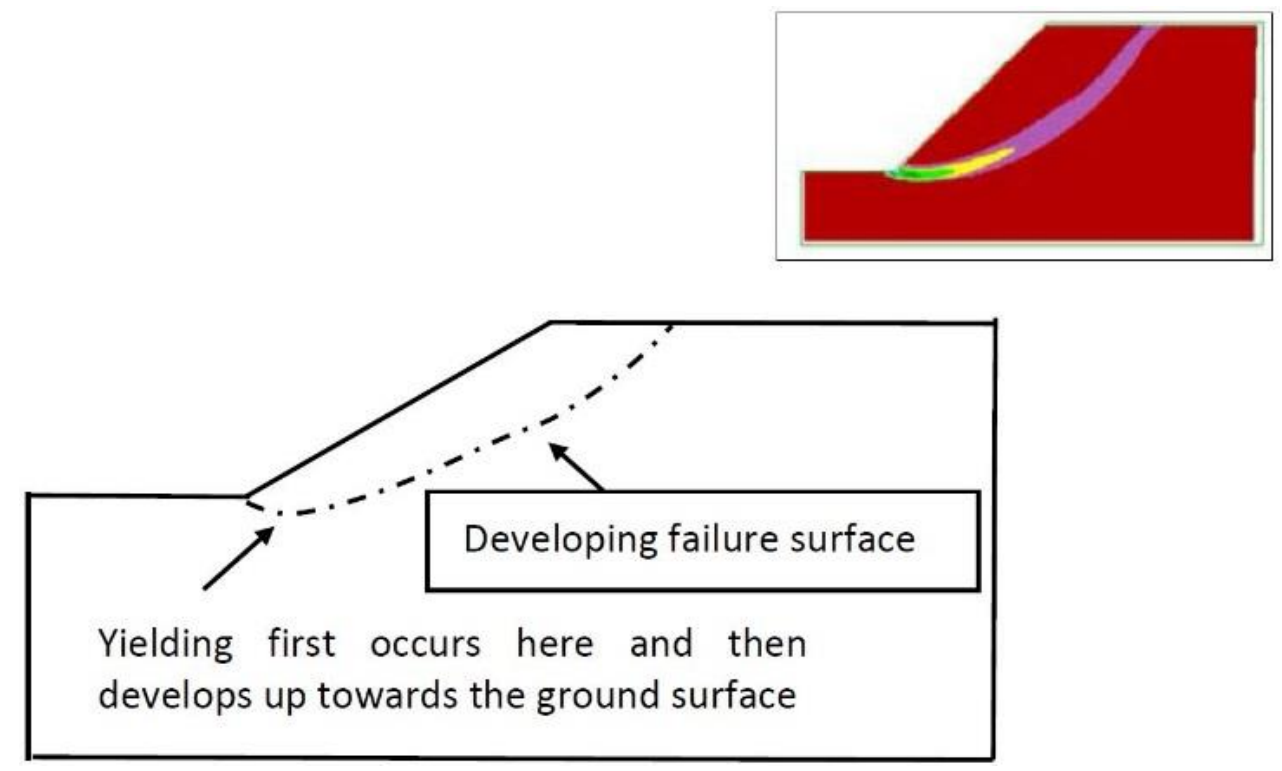

Figure 7 Illustration of how yielding first occurs near slope toe, then extends upwards towards the ground surface 
These results highlight a possible strategy to minimise the loss of the suction contribution to shear strength at the location where it is most needed, i.e. the toe of the slope. If, for example, water was allowed to pond at the toe of the slope, resulting in significant decrease in suction at the toe slope where the $C_{2}$ component is already mobilised and perhaps exceeded. In terms of strategies for taking advantage of the shear strength contribution from suction, the following suggestions are offered:

- Prevent accumulation of water at the toe of all slopes cut into saprolites. This may require the grading of benches to drain water away from the slope toe.

- After periods of protracted rainfall, if possible, excavate near-surface material, thus removing wet or saturated saprolite material. If this wet near-surface material is not removed, the excess water will be able to continue to migrate into the slope, decreasing suction where it is most needed in the vicinity of the highly stressed region shown in Figure 7.

\section{Conclusion}

There is potential to take advantage of the additional shear strength provided by negative pore water pressures (i.e. suction). This suction is a function of water content, with increasing water content resulting in decreased suction and thus decreased strength. Simple steps to reduce the potential ingress of moisture to a saprolite slope may produce significant dividends, enabling stability of the slope to be retained. Prevention of ponding at the toe of all saprolite slopes is essential and should be relatively easily achieved. A second option (although not to be considered in preference to preventing ponding) is to remove exposed slope faces immediately after a period of prolonged rainfall whenever possible.

\section{References}

Fookes, PG 1997, Tropical Residual Soils, Geological Society Publishing House, Bath.

Fourie, AB 1996, 'Predicting rainfall-induced slope instability', in Proceedings of the Institution of Civil Engineers, Geotechnical Engineering, vol. 119, pp. 211-218.

Fourie, AB 1997, 'Classification and index tests', in GE Blight (ed.), Mechanics of Residual Soils, Balkema, Rotterdam, pp 57-63.

Fredlund, DG, Morgenstern, NR \& Widger, RA 1978, 'The shear strength of unsaturated soils', Canadian Geotechnical Journal, vol. 15, pp. 313-321.

Fredlund, DG, Rahardjo, H \& Gan, JKM 1987, 'Non-linearity of strength envelope for unsaturated soils', in Proceedings 6th International Conference Expansive Soils, Balkema, Rotterdam, pp. 49-54.

Lao, DZ 2013, 'The stability of open pit mine slopes in residual soils', PhD thesis, The University of Western Australia.

Toll, DG 2012, 'The behaviour of unsaturated soils', in BBK Huat, DG Toll \& A Prasad (eds), Handbook of Tropical Residual Soil Engineering, Taylor and Francis, London, chapter 5.

Wang, YH \& Leung, SC 2008, 'Characterisation of cemented sand by experimental and numerical investigations', Journal of Geotechnical and Geoenvironmental Engineering, vol. 134, no. 7, pp. 992-1004. 
